\title{
P56 Renal Endovascular Interventions in Szeged Nephrology-Hypertension Center Between 2007-2016
}

Péter Légrády ${ }^{1, *}$, Bernadett Nádasdi ${ }^{1}$, Annamária Letoha ${ }^{1}$, Alexandra Gyói ${ }^{1}$, Dóra Bajcsi ${ }^{1}$, Kypros Constantinou ${ }^{1}$, Imola Fejes ${ }^{1}$, Endre Nagy², Tibor Szakál², Erika Vörös², Sándor Sonkodi ${ }^{1}$, György Ábrahám ${ }^{1}$

${ }^{1} 1$ st Department of Medicine, University of Szeged, Szeged, Hungary

${ }^{2}$ Radiology Department, University of Szeged, Szeged, Hungary

\begin{abstract}
There is no consensus on the antihypertensive effect and on the ability to preserve kidney function of ballon dilatations and/or stent implantation these in renal artery stenosis. From 2007 to 2016 at the 1st Department of Medicine, Nephrology-Hypertension Center, University of Szeged, total of 80 patients were diagnosed with unilateral or bilateral renal artery stenosis (female $n=49$; male $n=35$ ) with angiography. 80 of the patients underwent intervention (balloon dilatation $n=13$; stent implantation $n=67$ ). Following the intervention blood pressure significantly decreased and during the follow-up ( 3 months after the procedure, $n=54$ patients) the blood pressure remained below the initial level, while the number of antihypertensive drugs did not change significantly. The kidney function was also improved ( 3 months after the procedure, $n=54$ patients), except for patients with bilateral renal artery stenosis. There was a positive correlation between the resting, the separated plasma renin activity and systolic blood pressure. On the contrary, we did not find correlation between the severity of the renal stenosis and the separated renin plasma activity, and between the degree of stenosis and the ultrasound resistance index. Nevertheless, the resistance index correlated with the separated plasma renin activity. According to our results the renin release may depend rather on the state of the intrarenal microvasculature, than the degree of stenosis. Furthermore, the reason why the more severe stenosis is associated with worse kidney function - regardless the state of the microvasculature - may be the reduced kidney blood circulation caused by the stenosis cannot ensure appropriate intraglomerular pressure.
\end{abstract}

(C) 2019 Association for Research into Arterial Structure and Physiology. Publishing services by Atlantis Press International B.V. This is an open access article distributed under the CC BY-NC 4.0 license (http://creativecommons.org/licenses/by-nc/4.0/). 